\title{
EL DERECHO AL SILENCIO BAJO LA ÓPTICA DEL DERECHO COMPARADO
}

\author{
The RIGHT to SILENCE UNDER THE PERSPECTIVE OF COMPARATIVE LAW
}

\author{
Vladimir Orihuela Rojas* \\ Universidad Privada Antenor Orrego
}

\section{Resumen}

El autor inicia su análisis del derecho al silencio desde su concepción y regulación en épocas tempranas del derecho europeo, para luego identificar los rasgos inquisitivos que aún rigen sobre el mismo en el ordenamiento jurídico peruano; logra dar cuenta — en el camino_ de su importancia para la correcta administración de justicia.

Palabras clave: Derecho al silencio; prohibición de autoincriminación; presunción de inocencia; derecho de defensa.

\section{Abstract}

The author begins his analysis of the right to silence from its conception and the regulation in early times of European law, for identify the inquisitive features that are still on the Peruvian legal system, realizing that -in the way- of its importance for the correct administration of justice.

Keywords: Right to silence; prohibition of self-incrimination; presumption of innocence; right of defense.

* $\quad$ Doctor por la Universidad de Milán. Profesor en la Academia de la Magistratura. 
«El derecho a tener derechos o el derecho de todo individuo de pertenecer a la humanidad, debería ser garantizado por la humanidad misma.»

Hannah Arendt

«El hombre silencioso no presta testimonio contra sí mismo.» Aldous Huxley

La historia del derecho al silencio del imputado o del investigado es la historia del proceso penal en sí. Este hilo conductor conlleva, entonces, conocer la evolución de un Estado y conocer su grado de civilidad, tal como dijo un gran procesalista: «Si quieres conocer la democracia de un país conoce su proceso». O, a decir de la Corte Europea de los Derechos de Humanos, «el derecho al silencio es corazón mismo del proceso».

El proceso penal es siempre un lugar privilegiado de disputas entre el individuo y la autoridad del Estado. El nemo tenetur se detegere es un principio jurídico universalmente reconocido, pues su tutela se encuentra explícita o implícitamente en los tratados internacionales. Hoy el derecho al silencio es un baluarte de la cultura jurídica garantista.

\section{EXCURSUS HISTÓRICO DEL DERECHO AL SILENCIO}

\subsection{En el sistema de Civil law}

Los fundamentos históricos del derecho al silencio del encausado o imputado, tal como lo conocemos en la actualidad, podemos encontrarlos en la época del derecho común ${ }^{1}$, en tal período histórico la manifestación del imputado se utilizaba tendenciosamente en clave probatoria en el proceso penal. Posteriormente, tal declaración del imputado se consolida en el sistema inquisitivo - ya que fue la prueba legal típica de este sistema- que se degeneró en razón de los medios de coerción que se emplearon para hacer declarar al procesado, al cual se le obligaba e imponía a responder al interrogatorio (Grevi, 1972, pp. 7 y ss.).

En este sistema, el rol del procesado fue el de contribuir en la reconstrucción de los hechos; el imputado era tratado como fuente de prueba,

1 La forma procesal hoy definida como proceso penal de derecho común (europeo) o proceso penal del Antiguo Régimen o con una fórmula particularmente difundida en la cultura del proceso inquisitorio romano-canónico. 
el fulcro de esta forma de hacer proceso se sustentó en el primado de la tortura como medio de coerción para llegar a la verdad (Dezza, 2013, pp. 4 y ss. $)^{2}$, y, por ende, lograr la confesión del procesado. La tortura fue un medio para lograr la reina de la prueba — regina probationum —, que era la confesión del imputado.

A finales de los siglos IX y X, las instituciones carolingias entraron en decadencia en Europa, las nuevas clases sociales emergentes, tales como los vasallos de los condes y de los cardenales, los juristas y mercantes, ejercieron un rol influyente en la sociedad. A mitad del siglo X, debido al rápido desarrollo económico de la sociedad de ese entonces, las nuevas clases se reforzaron con los artesanos y los terratenientes. En el siglo XI aparecen las comunas como organizaciones políticas de gobierno provisionales constituidas por pocos miembros, posteriormente estas logran tener consenso social y centralizan el poder político de gobierno de la sociedad de aquel entonces; esta forma de gobierno adquiere autonomía legislativa, administrativa, fiscal y, sobre todo, obtienen reconocimiento de los reyes o emperadores. Esta autonomía legislativa se concretizó en los estatutos. En materia procesal penal las mismas se preveían en el sistema acusatorio.

Las comunas eran los nuevos sujetos políticos en el periodo histórico de la sociedad europea, acogían a personas provenientes de otras urbes, lo cual generó un incontrolable incremento de la población, facilitando de ese modo el surgir de nuevas formas de criminalidad. Tal situación condicionó que se modifique el modelo procesal originario - encuadrado en un modelo acusatorio - para dar más espacio al modelo inquisitorio, con el solo fin de salvaguardar la paz pública, mediante la represión de los delitos de mayor relevancia para la paz social. La organización política se hacía cada vez más compleja en esta borrasca, porque los organismos municipales llegaron a tener potestad jurisdiccional con poderes amplios con el solo fin de salvaguardar la paz pública, el reo era tratado como enemigo de la sociedad. En el sistema procesal, el reo tenía el deber de colaborar con la autoridad judicial, deber que era impuesto mediante la coerción física, psicológica, es decir, mediante la tortura.

2 La dicotomía entre acusa e inquisición es correlato al desarrollo de las instituciones políticas y sociales entre el medioevo y el moderno; toda la experiencia histórica del derecho común en Europa del siglo XII al XVIII era contraria al derecho romano y al derecho canónico, aplicando en la práctica la costumbre, dejando de lado la Ley y la doctrina, este modo de operar causó daño al modelo acusatorio. 
En Italia, entre los siglos XI y XIII, los estatutos de las comunas en materia procesal penal tenían un cierto favor en el uso del modelo acusatorio, en especial para las denuncias realizadas por privados o aquellas de naturaleza transactiva, la fuente primaria y prevalente era la costumbre. Como muy bien describe el profesor italiano Ettore Dezza (2013):

[...] sulla base di queste premesse, il XIII secolo si presenta come una vivacissima epoca di contraddizioni e di esperimenti, sia sul piano della giustizia pratica e quotidiana resa dai tribunali ecclesiastici e municipali sia a livello legislativo e dottrinale. Anche talune particolari fonti normative di ius proprium non sono esenti da forme di commistione: il Liber constitutionum dell'imperatore Federico II [1231], ad esempio, pur mantenendo l'ordinarietà del rito accusatorio, introduce una serie di procedure inquisitorie di carattere eccezionale (nei casi di flagranza, contri $i$ "famosi latrones», per reati di particolare rilevanza pubblica).

Sobre la base de estas premisas, el siglo XIII se presenta como un período muy animado de contradicciones y experimentos, tanto en términos de justicia práctica y cotidiana hecha por los tribunales eclesiásticos y municipales, tanto a nivel legislativo y doctrinal. Aunque algunas fuentes jurídicas del ius proprium no están exentas de estas formas de mixtura o unión: Liber Constitutionum del emperador Federico II (1231), por ejemplo, manteniendo el normal rito acusatorio, introduce una serie de procedimientos inquisitorios de carácter excepcional (en caso de flagrante delito, en contra de los «famosos ladrones», también en los determinados delitos de relevancia pública). [La traducción es nuestra].

Sobre la base de tal premisa, el siglo XIII se presenta como una época viva de contradicciones y de experimentos, ya sea en el plano de la justicia práctica y cotidiana realizada por los tribunales eclesiásticos y municipales, ya sea a nivel legislativo y doctrinal.

La forma de tratamiento que recibía el reo por parte de las autoridades generaron movimientos de discusión críticos a la forma de proceso penal. Uno de los movimientos fue la Escuela Iluminista italiana, que elaboró los presupuestos ideológicos críticos al sistema que admitía la tortura, obligaba al imputado al juramento; puntualizaban el carácter contra naturam de cada declaración autoincriminante, enfatizando el acto inmoral de los instrumentos empleados para obligar al imputado a la autoincriminación. Como es de reconocimiento universal, Cesare Beccaria fue uno de los más representativos iluministas italianos, al respecto, en su Tratado de los delitos y las penas, capítulo XVI. De la tortura, señala que ésta es 
[u]na crueldad consagrada por el uso entre la mayor parte de las naciones, es la tortura del reo mientras se forma el proceso, o para obligarlo a confesar un delito, o por las contradicciones en que incurre, o por el descubrimiento de los cómplices, o por no sé cuál metafísica e incomprensible purgación de la infamia; o finalmente, por otros delitos de que podría ser reo, pero de los cuales no es acusado.

Un hombre no puede ser llamado reo antes de la sentencia del juez, ni la sociedad puede quitarle la pública protección, sino cuando esté decidido que ha violado los pactos bajo que le fue concedida. ¿Qué derecho, sino el de la fuerza, será el que dé potestad al juez para imponer pena a un ciudadano, mientras se duda si es reo o inocente? No es nuevo este dilema: o el delito es cierto o incierto; si es cierto, no le conviene otra pena que la establecida por las leyes, y son inútiles los tormentos, porque es inútil la confesión del reo; si es incierto, no se debe atormentar un inocente, porque tal es según las leyes un hombre cuyos delitos no están probados. Pero yo añado, que es querer confundir todas las relaciones pretender que un hombre sea al mismo tiempo acusador y acusado, que el dolor sea el crisol de la verdad, como si el juicio de ella residiese en los músculos y fibras de un miserable. Este es el medio seguro de absolver los robustos malvados y condenar los flacos inocentes. Veis aquí los fatales inconvenientes de este pretendido criterio de verdad, pero criterio digno de un caníbal, que aun los Romanos, barbaros por más de un título, reservaban sólo a los esclavos, víctimas de una feroz y demasiada loada virtud» (Beccaria, 2015, p. 39). [Énfasis agregado.]

\section{La postura crítica del Marqués de Gualdrasco e de Villareggio, Cesare} Bonesana-Beccaria, con respecto a la tortura, no lo demuestra con respecto al derecho del reo a tener silencio, pues en el Capítulo XXXVIII referido a las Interrogaciones sugestivas y deposiciones en el Tratado de los Delitos y las Penas dice

[...] Finalmente, aquel que en el examen se obstinase, no respondiendo a las preguntas que se le hicieren, merece una pena determinada por las leyes; y pena de las más graves que entre ellas se hallaren para que los hombres no burlen así la necesidad de ejemplo que deben al público. No es necesaria esta pena cuando sepa de cierto que tal reo haya cometido tal delito, de tal modo que las preguntas sean inútiles, como lo es la confesión del delito, cuando otras pruebas justifican la criminalidad. Este último case es el más ordinario, porque la experiencia demuestra que en la mayor parte de los procesos los riesgos niegan (Beccaria, 2015, pp. 78, 79). [Énfasis agregado.]

Es muy clara la posición de Beccaria sobre el tema. Al respecto, Vittorio Grevi (1972) manifestó

[a] decir la verdad, la percepción de un desarrollo teórico en tal sentido no fue presente en todos los Iluministas, o no lo fue de manera completa. El mismo Beccaria no se dio cuenta de los concretos reflejos de su propia enseñanza. (p. 13) 
Las tesis iluministas de Cesare de Beccaria tuvieron gran influencia en Europa, tal es así que las tesis revolucionarias en materia penal convivían con aquellas tesis severas sobre la punición al reo que se obstinaba a no responder en el proceso penal. Sobre ello, la emperatriz Catalina II de Rusia en el año 1766 elaboró la Instrucción, que era una declaración de principios del buen gobierno, inspirada en las doctrinas de los filósofos Beccaria y Montesquieu. En tal periodo convocó a una comisión a fin de que codifique el derecho inspirándose en sus ideas directrices, tal comisión no tuvo buen éxito, ya que se disolvió dos años después. De igual modo, las ideas de Cesare de Beccaria influenciaron en el Código Penal austriaco de 1803, llamado Código Penal «Universal» del 1803 (Vinciguerra, 1993, p. 9), el cual rigió para todo el imperio austriaco, que en aquella época comprendía la parte del norte de Italia, que hoy sería la región de Lombardía, incluido Milán, ciudad de donde era originario el aristócrata Beccaria. En tal cuerpo de leyes, por un lado, se suprimió la tortura, pero, por otro lado, se continuaba con establecer severas medidas coercitivas, penas corporales que se le infligió al imputado durante el interrogatorio, y el castigo era peor si este se obstinaba a no responder. En la parte austroitaliana, el trato al imputado era más vil, al decir que el imputado que se obstinaba en guardar silencio «no deberá, tener por tres días pan y agua, después de la reiterada amonestación deberá ser castigado a bastonadas por tres días, en modo que iniciando con diez golpes se aumente en número progresivo de la pena corporal.»

Es preciso recordar y hacer presente que también en tal periodo históricoexistió otro gran iluminista italiano ${ }^{3}$ Gaetano Filangieri, quien en su

3 Vittorio Frossini dice sobre Filangieri: «Con la grande obra de Filangieri, por la segunda vez en el siglo XVII la cultura jurídica italiana se enaltecía con este representante de la civilidad jurídica europea. En el año 1764 apareció el opúsculo de Cesare Beccaria, Dei Delitti e delle penne, que fueron los gritos que revolucionaron la conciencia civil contra la barbarie judicial de la tortura y de la pena de muerte, la cual fue traducido por primera vez en francés en el año 1766, para luego ser traducido en catorce lenguas. La "Ciencia de la legislación» se publicó en Florencia en el año 1782, en Venecia en el año 1782, en Milano en el año 1784, en Catania en 1786; en el año 1784 fue traducido en alemán, en el año 1787 se tradujo al castellano, en el año 1783 parcialmente en ruso, en inglés en el año 1806, en sueco en el año 1814. [...][E]n el tratado de Filangieri, éste analiza la obra de Beccaria [al cual conoció], apreció la obra, como también lo criticó, él representa la cultura iluminista de Napoli (Frossini en Filangieri, 1984, p. X). 
obra Ciencia de la legislación, publicada en Nápoles en el año 1780, al realizar un disquisición sobre la tortura y, por ende, la confesión dice

[si el lector me consciente, he realizado una traducción de la reimpresión de la obra del 1780 sobre el pensamiento de éste gran iluminista partenopeo, acerca de la temática que estamos desarrollando, porque es de una docta disquisición erudita que comparto con ustedes]: ¿Cuál es el motivo por el cual se da la tortura? Se recurre a éste feroz experimento para obtener del reo la confesión de haber cometido el delito, o para tener conocimiento de los cómplices que han colaborado en la violación a la ley. El primer motivo es el más frecuente. Veamos sobre qué derecho puede ser fundado. Se supone que el acusado al cual se inflige la tortura es efectivamente culpable de aquel delito por el cual es acusado, y que para condenarlo se necesita su confesión por defecto de las pruebas. En esta hipótesis, yo me pregunto, ¿el magistrado tiene el derecho de pretender del reo la confesión de la comisión del delito? A cada derecho se supone que corresponde una obligación. Si el magistrado tendría este derecho, el reo, por lo tanto, tendría el deber de revelarle la comisión del delito. Ahora bien, ¿̇un deber contrario a la primera ley natural, puede ser un deber? La primera ley de la naturaleza es aquella que nos obliga a la conservación de nuestra propia existencia. Si a pedido del magistrado sobre la verdad de la acusación que es contra mi persona, yo fuese obligado a confesar el delito cometido, y si esta confesión conlleva a la muerte, yo me encontraré en este caso entre dos deberes opuestos, y no podría satisfacer el uno sin violar el otro. Si el pacto social me obligase a esta confesión, el pacto social me obligaría a violar una ley natural anteriormente predeterminada: el pacto social sería nulo. Si el pacto social me obligase a confesar mi delito, el mismo pacto obligaría, aunque, a cualquier reo de cualquier delito, de someterse espontáneamente a las manos de la justicia para sufrir el meritado castigo. Entonces éste pacto social se degeneraría, en este caso, en un pacto evidentemente contrario a la naturaleza de los pactantes. No es este el espíritu de aquella primitiva convención que todos los individuos de la sociedad implícitamente ratifican. La segunda parte de una ley dice Hobbes, es decir aquella que contiene la sanción penal no es más que una orden directa a los magistrados. En efecto, no hay ley que ordene al ladrón o al homicida a ir espontáneamente a la horca.

Si el reo no tiene el deber de confesar la comisión del delito, como se ha demostrado, el magistrado no puede — por tanto - tener el derecho de exigir de éste la confesión. Si el reo violase una ley eterna de la naturaleza, confesando su capital delito, el magistrado condenándolo a los tormentos de la tortura para inducirlo a confesar, castiga; por lo tanto, un silencio en él, sin violar la ley de la naturaleza que le obliga a guardar silencio. (Filangieri, 1984, p. 448)

\section{Dezza (2013) sostiene}

[d]a tale disegno scaturisce un procedimento nel quale si manifestano due principi ricorrenti nel pensiero Filangieriano, individuabili l'uno nel ruolo 
decisivo attribuito alla legge e alla sua esatta applicazione, l'altro nella insopprimibile esigenza di difendere la dignità, la libertà e i diritti del cittadino (p. $121) .{ }^{4}$

[...] de tal diseño se extrae un procedimiento en el cual se manifiestan dos principios recurrentes en el pensamiento filangieriano, individualizados, por un lado, en el rol decisivo tiene la Ley y su exacta aplicación, de otro en la insuprimible exigencia de defender la dignidad, la libertad y los derechos del ciudadano [Traducción propia].

Es necesario epitomar la obra de Thomas Hobbes ${ }^{5}$, en la cual se puede apreciar que ninguno ser humano está obligado a la autoincriminación, parafraseando al autor: igualmente no tiene validez un pacto en el que uno declara en contra sí mismo, sin la seguridad del perdón. En la condición natural de hecho, en que cada hombre es juez, no existe puesto para la acusa (Hobbes, 2006, p. 114).

Es innegable el gran aporte de los pensadores iluministas (ilustración, lumieres) y en especial de los iluministas italianos ${ }^{6}$ (Capone, 2006, pp. 5515 y 5516), en el haber elaborado los presupuestos filosóficos para desterrar la falsa idea de que el imputado estaba obligado a colaborar a cualquier costo con el juzgador (argumentos avalados por la doctrina del pasado). La reacción iluminista contra un tipo de proceso que consideraba al imputado como un simple objeto de prueba produce todo un cambio en el modo de entender el rol procesal que juega el imputado en el proceso (Grevi, 1972, p. 8).

\subsection{En el sistema del common law}

El derecho al silencio surge en Inglaterra en base a la creatividad jurisprudencial y a la valentía en un primer momento del juez Dyer, quien, en el año 1568, siendo presidente del Court of Common Pleas, concedió un habeas corpus con el cual se liberó a un imputado que había sido forzado a la autoincriminación; el argumento de su decisión fue nemo tenetur seipsum

4 Dezza afirma «Filangieri, en su obra Scienza della Legislazione, dedica un rigoroso estudio al proceso acusatorio diseñado y detallado analíticamente que hoy está en boga al menos en Europa.

5 Ferrajoli (1990) señala que «Nemo tenetur se detegere es la primera máxima del garantismo procesal acusatorio enunciada por Hobbes y recibida a partir del siglo XVII en el derecho inglés» (p. 623).

6 La ilustración en Italia se introdujo especialmente por los pensadores franceses, es claro que la ilustración italiana no fue simple repetición de la ilustración francesa, es así que surgió y se consolidó en el medio intelectual la denominada «filosofía de la experiencia». 
prodere (ningún hombre podrá ser forzado a producir evidencia contra sí mismo). Pero el verdadero caso relevante es el caso de John Lilburne, más conocido en el argot jurídico como el caso del señor Freeborn, en el cual el derecho al silencio encontró su histórico reconocimiento. John fue un acérrimo opositor al sistema monárquico; denunciado y condenado es llevado al Star Chamber -órgano Judicial competente para conocer los delitos contra la autoridad del Estado, el cual tenía el poder de utilizar la tortura, disponer el traslado coactivo del investigado y de interrogarlo bajo juramento - por importar e imprimir libros de carácter sedicioso y herético. En 1648, la Cámara de Lords acogió el recurso de Freeborn John y declaró nula la sentencia. Fue al final de 1600 que el derecho a la no autoincriminación se consolidó no solo en los tribunales Eclesiásticos, sino también en todas las jurisdicciones del common law (Di Bitonto, 2008, p. 33; Fanchiotti, 1999, pp. 507 y ss.). ${ }^{7}$

\section{EL DERECHO AL SILENCIO EN LA ACTUALIDAD}

En la época contemporánea, el reo se encuentra al centro del proceso penal, ya sea en el ejercicio de sus derechos y de sus obligaciones, éste es considerado en base a los derechos que le son inherentes, los cuales encuentran su fundamento a nivel local en el derecho constitucional, y a nivel internacional en las normas e instituciones sobre nacionales. Podríamos decir que el derecho constitucional y procesal penal se compenetran, por un lado, el derecho constitucional considera el derecho fundamental de la persona en su forma o posición estática, mientras el proceso penal lo considera al derecho fundamental de la persona en la forma dinámicaprocesal (Guarneri, 1954, p. 235). ${ }^{8}$

7 «Es una garantía reconducible a la elaboración conceptual madurada principalmente en los ordenamientos del common law en donde el derecho al silencio encontró pleno reconocimiento a mita del siglo XVII, cuando fue sancionado el juramento ex-officio al acusado de frente a la corte Eclesiástica. El reconocimiento explícito de este derecho se puede encontrar en $\mathrm{V}$ enmienda de la constitución federal de los Estados Unidos de américa 1971 donde establece«a nadie se le compelerá a declarar contra sí misma en ningún juicio criminal» (Fanchiotti, 1999, pp. 507 y ss.). El caso de los Estados Unidos de América ha sido muy tortuoso y polémico al respecto.

8 Agrega el autor «como la personalidad moral del imputado no podría degradarse a simple objeto de investigación, sino solo por necesidad y en los límites establecidos por Ley, por más que él se haya manchado de un delito, queda siempre un sujeto dotado de dignidad humana. Y esto se deberá tener en cuenta en sede de investigación para la adquisición de la prueba; re- 
En este binomio dialéctico de valores y leyes, el derecho al silencio nace como límite al extra poder de la autoridad judicial, de ese poder autoritario en el momento de interrogar al imputado. Se origina también como forma de protesta en contra de aquellos que hacían del proceso penal un proceso arrogante, mezquino, prepotente, que no conocía límites y mucho menos respetaba garantías que podía tener cualquier ser humano. El derecho al silencio es un valor, reconocido y protegido al interno del proceso, es un derecho que defiende la vulnerabilidad del imputado en el ámbito de la relación con la autoridad.

Parafraseando a Franco Cordero, citado por Giovanna Stanzione (2017, p. 3): «Existe un espacio en el ser humano, el suum, que es el recinto del Yo, que incluso el derecho no puede penetrar, es el derecho a la inviolabilidad del alma. El derecho al silencio es la puerta que cierra aquel recinto, en el proceso penal hace que el imputado, y solo él elige abrirlo o cerrarlo».

Por fines didácticos acerca del derecho al silencio, hemos dividido su estudio en: silencio en el sistema inquisitivo y silencio en el sistema acusatorio.

\subsection{El silencio en el sistema inquisitivo}

En este sistema, el imputado era visto con sospecha, indicio suficiente para condenarlo y conducirlo a la tortura. El interrogatorio era el corazón de todo el procedimiento, el momento central de la acusación era el interrogatorio, y el reo tenía la obligación de decir la verdad, en caso contrario el juez acusador disponía de cualquier medio para ejercer presión psicológica o física, a fin de obtener la respuesta del reo. Al decir de los historiadores, el padre legítimo de la tortura es el interrogatorio. Aquí las dos figuras procesales se unían para formar el binomio acusador y juez, la sujeción del imputado era de sumisión al poder de la autoridad judicial. El silencio era el enemigo del proceso, es evidente aquí ese poder ilimitado del juez-inquisidor en la verificación de los hechos, según el cual ningún precio es demasiado alto, cuando el objetivo es la búsqueda de la verdad material ${ }^{9}$

sultando así que los métodos o procedimientos probatorios contrarios a la ética o las normas jurídicas de tutela de los derechos de la personalidad son inadmisibles en el proceso.»

9 Verdad sustancial o material, es decir, una verdad absoluta y omnicomprensiva en orden a las personas investigadas, carente de límites y de confines legales, alcanzable con cualquier medio más allá de rígidas reglas procedimentales. Es evidente que esta pretendida verdad sustancial, al ser perseguida fuera de reglas y controles y, sobre todo, de una exacta predeterminación empírica de las hipótesis de indagación, degenera en juicio de valor, de hecho ampliamente 
y la represión de la criminalidad ${ }^{10}$. Con el uso de la fuerza, el imputado es llamado a hacerse acusador de sí mismo, convirtiéndose así en fuente de prueba en su mismo proceso. El imputado se convierte en colaborador del juez-acusador, con el único fin de que no se paralice la máquina de la justicia.

\subsection{El silencio en el sistema acusatorio}

Previamente, debemos decir que el sistema acusatorio vive de principios imprescindibles: el principio de separación entre acusa y órgano que decide, la formación del saber procesal se basa en el contradictorio entre las partes, quienes presentan tesis y antítesis que deben componerse en la síntesis de la decisión de un juez, tercero e imparcial. El principio de presunción de inocencia, la inviolabilidad de la defensa, los cuales presuponen la tutela de la libertad moral del imputado y de su autodeterminación. El imputado ya no es más medio de prueba, es tratado como persona como sujeto titular de derechos y destinatario de garantías.

El acusador, en su posición privilegiada, tiene la carga de la prueba de la culpabilidad del imputado, respecto de su presunta inocencia. La valoración de la prueba es regulada de un conjunto de normas rigurosas, normas que delimitan la actividad de conocimiento del juez.

Para que se pueda decir que un proceso penal sea garantista en cuanto al derecho al silencio, es necesario delimitar dos cosas: por un lado, la prerrogativa punitiva del Estado, donde demuestra su autoridad, pero también donde demuestra su propia función en reconocer al imputado o indagado el derecho inviolable al silencio y a no participar a la propia autoincriminación. Por otro lado, es innegable que el órgano acusador en la etapa de las diligencias preliminares, tiene una posición fuerte y privilegiada, el derecho al silencio trataría aquí de reequilibrar o de balancear posiciones.

Illuminati (1988), al referirse a estos dos sistemas procesales, señala que

[...] surgieron con grande determinación dos modelos culturales, un diverso modo de entender las relaciones entre el ciudadano y la autoridad del Estado. Surge la afirmación según el [sic] cual el proceso acusatorio sería la expresión de los regímenes democráticos y el proceso inquisitivo de los regímenes autoritarios (pp. 1-10).

arbitrario; así como que el cognoscitivismo ético sobre el que se basa el sustancialismo penal resulta inevitablemente solidario con una concepción autoritaria e irracionalista del proceso penal (Ferrajoli, 1990, p. 17).

10 Stanzione (2017, p. 7) hace referencia a Nobili. 


\section{ONTOLOGÍA DEL DERECHO AL SILENCIO}

\section{1. ¿Qué tutela el derecho al silencio?}

El proceso penal tiene como fin principal la persona humana, verdad innegable en caso de la dignidad del imputado.

Todas las libertades, todos los derechos son banales, si el proceso no es fundado en el respeto de la dignidad de la persona humana. El principio de la dignidad humana es uno de los principios supremos intangibles de los ordenamientos constitucionales modernos (Stanzione, 2017, p. 22).

$\mathrm{Al}$ respecto, Francesco Viola, el filósofo del derecho, nos ilustra que la dignidad humana se ubica por encima de los ordenamientos jurídicos, de los sistemas políticos y de las doctrinas morales. Comprender el concepto de «dignidad humana» es entender en qué consiste esta calificación normativa atribuida al ser humano. Dignitas indica excelencia o superioridad moral. ¿En qué consiste esto? ¿Es propio sólo del ser humano? ¿En qué modo debería ser justificado? En este sentido, las teorías de la dignidad humana se dividen en dos categorías: Las que unen este valor moral a determinadas características ontológicas; y aquellas que lo hacen depender de factores de progreso que influyen en el desarrollo histórico del ser humano. A la primera la denomina teoría de la dotazione, y a la segunda, teoría de la prestación. Para la primera teoría todo ser humano tiene dignidad desde el momento de su existencia, desde el momento que nace, ya el solo hecho de existir le atribuye una dignidad. En cambio, la teoría de la prestación es más focalizada al mérito, al poder, a la virtud, a los logros personales, a los resultados del quehacer humano y el de construir su propia identidad (Viola, 2006, pp. 2863-2865; Viola, 2008, pp. 102 y ss.) ${ }^{11}$.

11 Viola (2006) señala que «La ética de los derechos, hoy prevalente, se basa en la idea que a todos los seres humanos se le debe una igual consideración, respeto y que la dignidad humana es inviolable. Que incluso el peor delincuente tiene una dignidad humana por el solo hecho de ser hombre» (p. 2864)». Vincenti (2009, p. 12) refiere lo siguiente: «El carácter de élite era más visible en la dimensión política social en el mundo romano donde el término Dignitas era usado para indicar el rango o grado y esto era ligado al mérito y por lo tanto la disparidad de uno contra el otro era de si evidente. Es menester hacer referencia el siglo de la Ilustración, los grandes temas que exaltaron en un primer momento fueron la razón, la libertad, el rechazo al principio de autoridad, para llegar luego a la defensa de su dignidad». Kant (2007, pp. 47 y 48) dice «En el reino de los fines todo tiene o un precio o una dignidad. Aquello que tiene precio puede ser sustituido por algo equivalente, en cambio, lo que se halla por encima de todo precio y, por tanto, no admite nada equivalente, eso tiene una dignidad». 
La dignidad humana se traduce en la libertad como autonomía para determinar sus propios fines. Se puede inferir que la mortificación de la dignidad sigue a situaciones en las que se revela la sujeción de un hombre a otro, con la privación de la libertad de autodeterminación, y se perpetúa cuando el hombre es reducido a herramienta (D’Agostino, 1993, pp. 252 y ss.).

En nuestro ordenamiento constitucional, la dignidad humana ${ }^{12}$ está configurada como un valor jurídico, tiene naturaleza fundamental; la dignidad es un valor, una entidad ideal, en el común pensar y sentir es reconocida en positivo, y es destinataria de reconocimiento privilegiada en términos de tutela y protección fuera de la realidad jurídico-normativa. Tiene eficacia vinculante, tiene sustento constitucional, su dimensión jurídica es bien definida; en síntesis, es un valor que ha pasado a ser un derecho positivo.

Se define a la dignidad de la persona como valor superior (España), principio jurídico de valor constitucional (Francia), también se expresa como derecho subjetivo como ocurre en la Constitución alemana y en otros textos constitucionales.

La dignidad de la persona también constituye el fundamento de todos los derechos humanos, siendo así el núcleo o germen de los derechos (Vernet, 2011, pp. 425 y ss.). Por tal motivo, el respeto de la dignidad impide tratar a cualquier hombre como un objeto o instrumento, sea por parte del Estado o de los demás. En consecuencia, la dignidad de la persona se relaciona con otros principios o valores constitucionales, como la libertad, igualdad y justicia.

El principio de la dignidad del imputado debe representar el respeto a la idea misma del proceso. La dignidad del imputado es la medida de valor de la disposición procesal y es la medida del valor de todo el proceso. El principio de la dignidad del imputado en el proceso penal debe ser seguido de un específico tratamiento jurídico en varias fases o grado del

12 Constitución Política del Perú 1993. "Artículo 1. La defensa de la persona humana y el respeto de su dignidad son el fin supremo de la sociedad y del Estado». I «Artículo 3. La enumeración de los derechos establecidos en este capítulo no excluye los demás que la Constitución garantiza, ni otros de naturaleza análoga o que se fundan en la dignidad del hombre, o en los principios de soberanía del pueblo, del Estado democrático de derecho y de la forma republicana de gobierno. [Énfasis agregado].

La primera referencia la encontramos en el preámbulo de la carta de Naciones Unidas de 1945. «a reafirmar la fe en los derechos fundamentales del hombre, en la dignidad y el valor de la persona humana, en la igualdad de derechos de hombres y mujeres y de las naciones grandes y pequeñas». [Énfasis agregado]. Es así como se expande en el constitucionalismo moderno. 
proceso que tutele efectivamente tal posición, porque si no el valor superior quedaría en un vacío de palabras o sería un canto de sirenas.

La dignidad actúa principalmente como límite muy claro a la acción del poder público en el ámbito del proceso penal, pero también actúa en forma implícita en cada derecho reconocido y garantizado al imputado en defensa de su propia persona. La dignidad del imputado es, entonces, un super principio con un contenido mínimo de los derechos de la persona.

Para citar las palabras de Stazione, si se subordinara la dignidad del imputado a los fines públicos o privados del proceso — justicia, verdad, aplicación de la ley, la emisión de la sentencia, punición del culpable-, se elaboraría una excesiva inversión en cuanto a perspectiva: no es la dignidad que debe ser subordinada a los fines del proceso, es más bien el objetivo del proceso el que se debe armonizar con la dignidad.

El derecho al silencio firmemente condensado a la protección del sujeto de cualquier intromisión moral a la no autoincriminación representa una garantía ineludible en un proceso penal inspirado en valores constitucionales. Como muy bien lo resume Roxin, «el derecho procesal penal es el sismógrafo de la Constitución Política del Estado.» (Claus, 2003, p.10).

\section{ASPECTOS DEL DERECHO AL SILENCIO}

\subsection{Aspecto estático}

El derecho al silencio del imputado tiene un aspecto estático, o sea, es un hecho, un comportamiento y su contenido será más o menos negativo según la interpretación que se podrá o deberá dar. Hay dos posiciones en el momento de la manifestación del derecho al silencio; primero, la conducta del que está en silencio; segundo, la conducta de quién interpreta el acto silencioso; es así cómo el intérprete del silencio es llamado a llenar el significado del espacio vacío creado por la ausencia de palabras.

\subsection{Aspecto dinámico}

El derecho al silencio en su aspecto dinámico está relacionado con otros derechos como el derecho a la libertad moral, con el derecho a la defensa, con el derecho a la presunción de inocencia. 
Ahora bien, Giuliano Vasalli (1972) decía que la libertad moral se presenta en buena sustancia como derecho a no tener que sufrir ilícitas intromisiones de otros en la propia esfera psíquica y en la formación de la conciencia y del pensamiento ya que estos se encuentran vinculados en la formación de la voluntad (pp. 393 y ss.).

\subsubsection{La libertad moral}

Es más que nada libertad negativa, su ámbito de acción es la relación entre individuos en el seno de la organización social, en la relación entre individuo y Estado, donde se percibe la libertad de autorrealización de la persona como libertad de desarrollo libre y autónomo con la propia interioridad y con el propio cuerpo-libertad.

A la libertad moral, en la actualidad dentro el proceso penal, se le dan formas que tratan de menoscabarla, o sea, mediante el uso de los métodos de la neurociencia en la búsqueda de la verdad procesal. Por ende, se regresa entonces a la vieja idea que reduce a la persona a un simple objeto de prueba, esta técnica de memory detection, el test a-I.A.T. [Autobiographical-IAT], sirve para verificar la fiabilidad del testimonio, es un procedimiento invasivo al interior de la mente de un sujeto ${ }^{13}$.

El uso de esta técnica, denominada neurociencia, para verificar la veracidad de la declaración de una persona genera mucha perplejidad, por más que existan criterios estables en la adquisición de la prueba científica, este método es lesivo a la libertad moral del sujeto declarante.

En nuestro ordenamiento, el uso de este instrumento está prohibido taxativamente por el Código Procesal Penal en cuanto perjudica la libertad moral de la persona. Pero por ironías del destino, el Tribunal Constitucional peruano ha admitido su uso en el ámbito laboral. ${ }^{14}$

13 En los últimos años se está asistiendo a un notable desarrollo de la neurociencia, la cual, estudiando la relación entre el cerebro y el comportamiento humano, acarrea contribuciones útiles no sólo en campo científico, sino también en el ámbito jurídico. La neurociencia ha contribuido con la técnica neuroimaging y el análisis genética, resultados útiles para la evaluación de la imputabilidad y para la determinación de la pena en concreto. Algeri, L. Neuroscienze, infermità di mente e credibilità del dichiarante. Diritto penale e processo. 11/2013, p. 1354. Kostoris, R. (2014). Genetica, neuroscienze e processo penale: brevi considerazioni sparse. Rivista di diritto processuale; p. 559.

14 El caso «Polígrafo», recaído en el Expediente N. ${ }^{\circ} 00273$ 2010-PA/TC, Sindicato Unitario de Trabajadores de Electrolima Empresas Concesionarias Eléctricas y afines-SUTEECEA. Pero el contrasentido viene a gala cuando en el fundamento 5 dice:«De otro lado, las conclusiones 
Hay que destacar que el derecho de no incriminación encuentra su justificación y fundamento en el derecho a la libertad moral ${ }^{15}$, es decir la libertad de conservar la propia personalidad psíquica, la libertad de razonar libremente, la libertad de no ser engañado ni coaccionado, el derecho a no verse injustamente impuesto a un comportamiento, sea este pasivo o inerte.

A nivel europeo, la Corte de Estrasburgo, la Sección V, presidida por el juez Villiger, en la causa entre el señor Yuriy Volkov contra el Estado de la Ucrania, en la fecha 19 de diciembre del 2013, ha dicho en lo referido a la no autoincriminación: «La presencia de un abogado debe ser garantizada [...], desde el primer interrogatorio, con el fin de proteger al acusado contra la autoincriminación y en contra de posibles malos tratos o abusos.». ${ }^{16}$

\subsubsection{El derecho a la defensa}

Como hemos dicho anteriormente, el aspecto dinámico del derecho al silencio se relaciona con el derecho a la defensa, es decir, éste tiene un estrecho vínculo con la libertad de autodeterminación y con la libertad moral. El acusado debe ser libre en decidir cómo actúa en defensa de su derecho, esto es, defendiéndose, probando o haciendo uso de su derecho al silencio. En esta cadena surge también el derecho a la autodefensa, que tiene vínculo jurídico y moral en base al principio nemo tenetur se detegere, es decir, nadie puede ser obligado a actuar en daño propio, a la autodefensa la podemos clasificar en: pasiva y activa.

del examen del polígrafo pueden ser utilizadas como elemento de justificación para el inicio de un procedimiento o una investigación, pero no pueden ser utilizadas para la determinación de las responsabilidades a que hubiere lugar pues, como es sabido, la validez de la determinación de las responsabilidades en términos constitucionales exige que exista prueba suficiente que sea capaz de desvirtuar la presunción de inocencia». La pregunta sin respuesta es entonces ¿qué busca todo procedimiento o investigación?, acaso no busca responsables, someter al polígrafo a una persona busca la verdad y la responsabilidad o es un lujo de empresa someter a actos indignos a sus trabajadores.

15 En la Constitución Política del Perú de 1993, en su artículo 2, inciso 24, literal h, se refiere que «[n] adie debe ser víctima de violencia moral, psíquica o física, ni sometido a tortura o a tratos inhumanos o humillantes. Cualquiera puede pedir de inmediato el examen médico de la persona agraviada o de aquélla imposibilitada de recurrir por sí misma a la autoridad. Carecen de valor las declaraciones obtenidas por la violencia. Quien la emplea incurre en responsabilidad.» [Énfasis agregado]. Sabatini, G. (1962). Poligrafo e libertà morale. Giustizia penale; p. I, 1.

Osservatorio Corte europea dei diritti dell'uomo a cura di Carlotta Conti. 


\subsubsection{La autodefensa pasiva}

Se representa en tres diversos aspectos del principio nemo tenetur se detegere - trasplantado del proceso del Common law-, el derecho a no ser interrogado por el juez — right not to be questioned - el derecho a la no autoincriminación — privilege against self incrimination - y el derecho al silencio (Catalano, 2011, p. 4018) ${ }^{17}$.

\subsubsection{La autodefensa activa}

Es decir, el derecho a mentir. Esta forma de autodefensa fue rechazada en la época moderna, e incluso por el procesalista Carnelutti, porque era contraria al derecho a la mendicidad; por el contrario, la declaración del imputado era la oportunidad de reconocer y obligar a decir la verdad, la influencia carneluttiana creó la ideología de la carga de la verdad. Esta ideología decía que el comportamiento evasivo y mentiroso del imputado debería de ser medio de prueba utilizable por el juez en base a la regla de la experiencia para la formación de su convencimiento. Por cierto, ya en filosofía ${ }^{18}$, la polémica entre verdad y mentira era muy conocida. En esta perspectiva de intolerancia, Francesco Carnelutti expresaba que el imputado es el único que sabe la verdad de los hechos y solo él los conoce y se le tiene que extraer la verdad (1947, pp. 165 y ss.). En la lógica de Carnelutti sería justo

17 Derecho a defenderse en silencio puede explicarse en base a dos modelos: el modelo ideológico jurídico y el modelo o sistema procesal. La tutela de la libertad moral de la persona encuentra espacio en el ámbito de un sistema acusatorio garantista y en el contexto de un orden político que gira en torno a la persona humana y quien a la vez no es subordinado al poder público.

18 Es lícito mentir, es un diálogo imaginario entre Constant y el filósofo alemán Immanuel Kant, que rechazaba radicalmente la mentira, porque haría imposible la construcción de una sociedad; la mentira es la degradación y, en cierto modo, la anulación de la dignidad de la persona, y afirma que decir la verdad es un deber absoluto. Constant, sin embargo dice que es posible mentir para proteger a un amigo, que el deber de la verdad es tal solo respecto a quien tiene derecho a la verdad (Kant \& Constant, 2012; Marcoaldi, 1996; Ramírez, 2004). En nuestra modesta conclusión la mendacidad es lícita según las circunstancias, situaciones y solo aceptable en caso de fuerte necesidad. La discusión acerca de la mentira no era un hecho novedoso. Muchos autores de la Antigüedad habían planteado situaciones similares a las que dieron origen a la polémica entre Constant y Kant. En el De mendacio, San Agustín propone el caso de las matronas hebreas que mienten a las autoridades egipcias para evitar la muerte de los neonatos varones [Ex. 1, 15-20], como muy bien nos detalla Juan Antonio Cabrera Montero (Gopnik, 2017, p. 31). Los grandes escritores usan la mendacidad como método para atraer lectores, mientras los tiranos lo usan solo para reforzar el dominio sobre otros (Cazzullo, 2015, p. 6). 
obtener forzadamente la colaboración del imputado a pacto de no usar métodos demasiados atroces, decía también que la pena era una medicina, un remedio, y que era necesario convencer al imputado a admitir su propia culpa. Esta lógica carneluttiana hoy por hoy no sería admitida, aunque existen rezagos inquisitivos en la actividad procesal.

Por un lado, desde un punto de vista filosófico, Benjamin Constant, y, por otro lado, desde el punto de vista jurídico, la doctrina italiana, entre otros, Franco Cordero y la jurisprudencia italiana se opusieron, sosteniendo que la mentira es Facultas agendi, y es intrínseca al ius tacendi. Al respecto el procesalista Cordero dice: «al imputado se le reconoce una soberanía en su libertad de acción, la que se exterioriza en un comportamiento silencioso o en una declaración mentirosa, y — sigue el autor- que el derecho de defensa incluye el de silencio y el de mendacidad».

En la teoría general del proceso, es común contraponer la acusa y la defensa. En la noción técnica de acusa y defensa, se observa que, en la primera, se afirma la hipótesis y la existencia de un hecho-delito, el fiscal solicita la punición, narra los hechos penalmente relevantes, en función explicativa se llama Tesis. En cambio la segunda — defensa—, evidencia el elemento más favorable que es la presunción de inocencia, proyectando así la antítesis; destinando ambas a ser superadas en la síntesis por la decisión del juez (Gardino, 1983, p. 1; Cavini, 2017, p. 169) ${ }^{19}$.

Se ha consolidado la tesis según la cual la defensa, además de integrar un derecho del imputado, también integra una condición de regularidad del proceso. De ahí la sugerencia que evoca una doble alma, por un lado, la defensa técnica cual elemento irrenunciable de la relación procesal penal, y por otro el derecho primario de rango constitucional, proclamado inviolable en todas las etapas y grados del proceso, condensado a ello la garantía para correcta verificación de los hechos ${ }^{20}$.

19 El autor refiere que el derecho a ser asistido por un abogado en el procedimiento penal y en la ejecución del arresto Europeo, el derecho a informar a un tercero al momento de la privación de la libertad y el derecho de la persona privada de su libertad personal de informar de inmediato a un tercero y a la autoridad consular. Con Decreto Legislativo N 184 del 15 de setiembre del 2016, el Estado Italiano ha implementado la Directiva Europea.2013/48/UE relativa a determinados aspectos del derecho de defensa del imputado.

$20 \mathrm{Al}$ respecto, Scaccianoce (2015) expresa «el imputado tiene derecho a permanecer en silencio y el derecho a mentir — conducta que, en la práctica, bien puede minar la existencia del proceso-; el imputado puede de hecho contaminar las pruebas, asumiendo las consecuencias procesales y sustanciales» (p. 56). Poner en el problema del abuso de la defensa en la óptica de 
La noción de defensa penal es muy controvertida, una parte de la doctrina la identifica como con la función dialéctica contra opuesta a la acusa, que el imputado — autodefensa- y su defensor — defensa técnica- ejercitan de frente a un juez imparcial (Ferrua, 1988, p. 466; Nappi, 2005, p. 370; Galati \& Zappala, 2001, p. 205; Bianco, 2016, p. 33. Musso, 1999, p. 7). ${ }^{21}$.

Doble es el fundamento del derecho de defensa, como función del proceso; por un lado, como derecho fundamental y, por otro, como garantía de la correcta verificación judicial. En el primero está en juego una opción de civilidad de tutela de la libertad, que marca un primado de los medios sobre los fines: un sistema de verificación preordenado al aplicar la pena no puede dejar al margen del proceso a quien es propenso a sufrirla. Se le debe consentir el diálogo, con igualdad de oportunidades, sin mayor título de quien tiene interés en la punición del culpable, es decir el acusador. El otro punto es la defensa como garantía objetiva, esta expresa una elección gnoseológica, eminentemente utilitaria, auxiliar a los fines del proceso. Aquí es donde se contraponen los razonamientos y las deducciones de la acusa y los razonamientos y deducciones de la defensa. En términos modernos, es la convicción de que la mejor manera de contrastar la validez de la acusa es instaurar el contradictorio entre quien formula la acusa y quien siendo imputado destinatario, tiene interés para refutar o contrastar los hechos imputados, irónicamente podríamos decir que es un abrazo a la discordia.

El derecho al silencio y la presunción de inocencia, en el libro áurea de Beccaria, en el título XVI de la tortura dice: «[u]n hombre no puede ser llamado reo antes de la sentencia del juez, ni la sociedad puede quitarle la pública protección, sino cuando esté decidido que ha violado los pactos bajo que le fue concedida. ¿Qué derecho, sino el de la fuerza, será el que

la defensa técnica abre escenarios delicados. Al respecto, el Tribunal Constitucional peruano reconoce también el doble alma del derecho de defensa en la sentencia recaída en el expediente N. ${ }^{\circ}$ 03597-2007-PHC/TC (considerando segundo), al referir «[q]ue el derecho de defensa tiene una doble dimensión: una material, referida al derecho del imputado o demandado de ejercer su propia defensa desde el mismo instante en que toma conocimiento de que se le atribuye la comisión de determinado hecho delictivo o la omisión del cumplimiento de una obligación; y otra formal, que supone el derecho a una defensa técnica; esto es, al asesoramiento y patrocinio de un abogado defensor durante todo el tiempo que dure el proceso.»

21 El autor evoca el artículo 24, 2 de la constitución italiana, que preceptúa: la defensa es un derecho inviolable en cualquier estado o grado del procedimiento. La inviolabilidad del valor «defensa», que el destinatario debe observar cada vez en que el valor viene en juego (Ferrua, 1988, p. 466; Nappi, 2005, p. 370; Galati \& Zappala, 2001, p. 205; Bianco, 2016, p. 33. Musso, 1999, p. 7). 
dé potestad al juez para imponer pena a un ciudadano, mientras se duda si es reo o inocente?» (2015, p. 39).

Hablar de la presunción de inocencia significa poner al centro de la discusión procesal la relación entre la persona y poder público, hacer prevalecer el primero sobre el segundo, de aquí recabamos cómo nace la fuerte conexión que une la presunción de inocencia ${ }^{22}$ a los sistemas garantistas de la justicia penal. En un Estado constitucional de Derecho, el modelo procesal tiene como referencia la tutela del inocente.

En doctrina se tiene que la presunción de inocencia tiene doble significado, por un lado, como regla de tratamiento que se dirige a tutelar al imputado y, por otro lado, la regla del procedimiento que sería el fulcro central del sistema acusatorio.

El derecho del imputado es también que la formulación de la acusa se sustente en válidos argumentos de cargo y de descargo; incluso si no existieran válidos fundamentos, el fiscal solicitará al juez según el numeral 2 del artículo 61 del Código Procesal Penal al referir que «2. Conduce la Investigación Preparatoria. Practicará u ordenará practicar los actos de investigación que correspondan, indagando no sólo las circunstancias que permitan comprobar la imputación, sino también las que sirvan para eximir o atenuar la responsabilidad del imputado. Solicitará al juez las medidas que considere necesarias, cuando corresponda hacerlo.» [Énfasis agregado].

Como dijo Beccaria (2015), «[t]oda pena, dice el gran Montesquieu, que no se deriva de la absoluta necesidad, es tiránica». Por lo tanto, la presunción de inocencia, garantiza el derecho al silencio del imputado a no participar o a no colaborar a la propia culpabilidad.

$\mathrm{Al}$ respecto, Mario A. Cattaneo ${ }^{23}$ nos dice que es evidente que el valor a la verdad, implica una rígida y celosa tutela a la inocencia, el proceso penal

22 Código Procesal Penal. Artículo II.- Presunción de inocencia. 1. Toda persona imputada de la comisión de un hecho punible es considerada inocente, y debe ser tratada como tal, mientras no se demuestre lo contrario y se haya declarado su responsabilidad mediante sentencia firme debidamente motivada. Para estos efectos, se requiere de una suficiente actividad probatoria de cargo, obtenida y actuada con las debidas garantías procesales.

23 Cattaneo (1995) hace referencia a los arrepentidos, colaboradores de justicia, en resumen dice que la inocua ley denominada de los «pentiti» ha puesto en peligro propio la tutela de la inocencia, atribuyendo a ciertos delincuentes oportunistas la calidad de grandes acusadores (p. 73). 
debe desarrollarse en manera clara y que no se deje llevar por indicios débiles y evite la pena a un inocente (1995, p. 73).

En la actualidad se ha consolidado la idea prevalentemente que los derechos individuales o subjetivos giran al centro del proceso penal; se ha consolidado también en nuestro medio que el estudio del proceso penal se realice desde una óptica constitucional (Alvazzi \& Serges, 1992, pp. 11 y ss.).

\section{EL DERECHO AL SILENCIO EN EL ORDENAMIENTO PROCESAL PENAL PERUANO}

El legislador peruano, haciendo suyo el patrimonio común europeo en materia de tutela de los derechos del investigado, del imputado, introduce en varios artículos del Código Procesal Penal peruano ${ }^{24}$, mecanismos de tutela a los derechos del investigado-imputado-persona.

La modalidad de actuación del derecho al silencio en el Perú se da en fase policial, fiscal y ante el juez, y en orden a los diversos momentos procesales, la autoridad tiene la obligación de advertir al imputado que tiene el derecho de abstenerse de declarar. El artículo 71 hace referencia muy explícita a la Policía Nacional, entre los sujetos que están vinculados en formular el advertimiento. Corroborado con una de sus atribuciones, en el artículo 68, «[1]a Policía Nacional en su función de investigación, sin perjuicio de lo dispuesto en el artículo anterior y en la normas sobre la investigación, bajo la conducción del Fiscal, podrá realizar lo siguiente: h) Capturar a los presuntos autores y participes en caso de flagrancia, informándoles de inmediato sobre sus derechos.» [Énfasis agregado]. Estas disposiciones aclaran cualquier duda acerca de la operatividad del derecho al silencio incluso en sede investigativa policial, en la parte que establece que la obligación de informar sobre los derechos que tiene toda persona — indagado, indiciado, encausada, imputado-. El espíritu garantista de nuestro Código coloca a

24 El numeral 2 del artículo IX del Título Preliminar del Código Procesal Penal establece que «[n]adie puede ser obligado o inducido a declarar o a reconocer culpabilidad contra sí mismo, contra su cónyuge, o sus parientes dentro del cuarto grado de consanguinidad o segundo de afinidad». Asimismo, en su artículo 71 señala, como uno de los derechos de los imputados, «[1]os Jueces, los Fiscales o la Policía Nacional deben hacer saber al imputado de manera inmediata y comprensible, que tiene derecho a: (...) d) Abstenerse de declarar; y, si acepta hacerlo, a que su Abogado Defensor esté presente en su declaración y en todas las diligencias en que se requiere su presencia(énfasis agregado). 
la persona humana al centro del esquema del proceso penal, disciplinando la relación entre órgano investigador y el investigado, lo hace con mucha cautela ya que la experiencia de un cercano pasado nos ha enseñado que, constantemente, se han utilizado mecanismos coercitivos para extraer palabras al investigado con el clásico método de la tortura. El punto de referencia para la tutela del derecho del imputado en primis es la Constitución Política y las convenciones internacionales sobre derechos humanos, el Código Procesal Penal debe ser interpretado a la luz de la Constitución, esto es la brújula, un mapa de orientación que ilustra la forma como debe ser un proceso penal moderno ${ }^{25}$.

25 La Corte Constitucional colombiana, mediante sentencia C-782/05, ha referido que «[h]a sido pues una preocupación constante del Constituyente colombiano, garantizar el principio de la no autoincriminación del imputado, pues él en ejercicio de su derecho de defensa tiene la posibilidad de hablar o de callar, es decir, sólo él tiene la facultad de decidir sobre su propia declaración. Ahora, los derechos de defensa y de no autoincriminación no se limitan a las prescripciones de derecho interno consagradas en la Constitución de 1991, sino en tratados internacionales, como el Pacto Internacional de Derechos Humanos (Ley 74 de 1968), y la Convención Americana de Derechos Humanos (Ley 16 de 1972), en los cuales se establecen unas garantías mínimas que recogen elementos sustantivos del derecho de defensa, los cuales ineludiblemente han de ser tenidos en cuenta, en virtud de lo dispuesto por el artículo 93, inciso segundo de la Carta Política, en el que se establece que: "[l]os derechos y deberes consagrados en esta Carta, se interpretarán de conformidad con los tratados internacionales sobre derechos humanos ratificados por Colombia"».

En ese sentido, es relevante traer a colación el artículo 8 de la Convención Americana de Derechos Humanos o Pacto de San José de Costa Rica, referente a las garantías judiciales, el cual consagra que:

«Toda persona tiene derecho a ser oída con las debidas garantías y dentro de un plazo razonable, por un juez o tribunal competente, independiente e imparcial, establecido con anterioridad por la ley, en la sustanciación de cualquier acusación penal formulada contra ella, o para la determinación de sus derechos y obligaciones de orden civil, laboral, fiscal o de cualquier otro carácter.

2. Toda persona inculpada de delito tiene derecho a que se presuma su inocencia, mientras no se establezca legalmente su culpabilidad. Durante el proceso, toda persona tiene derecho, en plena igualdad, a las siguientes garantías mínimas:

[...]

g) derecho a no ser obligado a declarar contra sí mismo ni a declararse culpable».

Por su parte, el Pacto Universal de Derechos Humanos, en su artículo 14 dispone lo siguiente: «1. Todas las personas son iguales ante los tribunales y cortes de justicia. Toda persona tendrá derecho a ser oída públicamente y con las debidas garantías por un tribunal competente, independiente e imparcial, establecido por la ley, en la sustanciación de cualquier acusación de carácter penal formulada contra ella o para la determinación de sus derechos u obligaciones de carácter civil $[\ldots]$.

2. Toda persona acusada de un delito tiene derecho a que se presuma su inocencia mientras no se pruebe su culpabilidad conforme a la ley.

3. Durante el proceso, toda persona acusada de un delito tendrá derecho, en plena igualdad, a las siguientes garantías mínimas: 
Es necesario aquí puntualizar que el derecho al silencio emerge y se consolida, en todos los ordenamientos modernos, en función de poner el límite al extrapoder de la autoridad judicial con respecto al imputado sometido a interrogatorio (Grevi, 1972, p. 6).

¿Cuál es la razón de ser del derecho al silencio? En este orden de ideas, es preciso aclarar que el derecho funciona cuando el acusado está en contacto directo con la autoridad, la razón es evitar que el sujeto acusado no pueda ser inducido en error o a malos entendidos, con la falsa esperanza y expectativa en dar declaraciones, respuestas y obtener supuestas ventajas en el proceso. Lo que se quiere es colocar límites a los abusos cometidos por la Policía Nacional, dejar de creer en la falsa idea de Carnelutti, que el imputado es el grande colaborador de la verdad, esa es una idea errónea.

Es común ver que en los procesos penales el imputado después de haber confesado el delito ante la policía o durante las diligencias preliminares, cuando está frente al juez, declara que su confesión fue extraída usando violencia o engaño (Luparia, 2006, pp. 31 y ss.). Por ello, bien hace nuestro Código Procesal, en el artículo 160, y preceptúa que la confesión: 2. Solo tendrá valor probatorio cuando: a) Esté debidamente corroborada por otro u otros elementos de convicción; b) Sea prestada libremente y en estado normal de las facultades psíquicas; c) Sea prestada ante el juez o el fiscal en presencia de su abogado; y, d) Sea sincera y espontánea. [Énfasis agregado]. Es necesario hacer referencia que el testimonio es también tutelado por este derecho, cuando se preceptúa en el numeral 2 del artículo 163 de nuestro Código Procesal Penal que el testigo no puede ser obligado a declarar sobre hechos de los cuales podría surgir su responsabilidad ${ }^{26}$, de igual manera

[...]

g) A no ser obligada a declarar contra sí misma ni a confesarse culpable».

Como queda visto, el proceso penal es un instrumento creado por el Derecho para juzgar, no necesariamente para condenar. También cumple su finalidad constitucional cuando absuelve al sindicado. Es decir, a éste le asiste en todo momento la presunción de inocencia y el derecho de defensa, consecuencia de lo cual se impone el in dubio pro reo, que lleva a que mientras exista una duda razonable sobre la autoría del delito y la responsabilidad del sindicado, éste acorazado con la presunción de inocencia debe ser absuelto.» [Énfasis agregado].

Recuperado de: http://www.corteconstitucional.gov.co/relatoria/2005/C-782-05.htm

26 Idéntico al Código Procesal Penal italiano, el cual refiere, en el numeral 2 de su artículo 198, que «Il testimone non può essere obbligato a deporre su fatti dai quali potrebbe emergere una sua responsabilità penale.» 
está disciplinado en el desarrollo del interrogatorio al señalar que «el testigo será instruido acerca de sus obligaciones y de las responsabilidades», pero el rezago inquisitivo llega a lo paradójico de lo paradójico cuando en propio artículo dice «y prestará juramento o promesa de honor de decir la verdad, según sus creencias", ¿`cómo se hace para descubrir la verdad? El numeral 3 del artículo 164 refiere que "[s]i el testigo no se presenta a la primera citación se le hará comparecer compulsivamente por la fuerza pública.» [Énfasis agregado] ¿Acaso esta compulsión no es violar la libertad moral?

El derecho al silencio es una toma de posición importante en la evolución del proceso penal, ya que como principio no incentiva a pretender la colaboración o presentación de elementos útiles de la persona sometida a investigación que le conlleve la propia culpabilidad. El derecho al silencio representa el reconocimiento de un cierto valor, en el caso en especie es el derecho de defensa (Corso, 2000, pág. 173 y ss.).

Se podría decir que el derecho al silencio va encuadrado en el más amplio derecho de imputado de no colaborar a la propia condena; en este sentido, el imputado tiene el derecho de no colaborar con su propio cuerpo o con la propia persona al proceso.

El derecho al silencio del imputado es solo sobre hechos propios y no sobre hechos de terceros. Cuando el imputado hace referencia a hechos de terceros, el derecho al silencio no es reconocido.

¿Qué valor probatorio tiene el silencio? El silencio del imputado puede producir una mala impresión, en el ánimo del fiscal o juez, más aun si se trata de personas poco sensibles a la exigencia de respeto de la libertad moral del imputado, tal impresión en teoría no podría influenciar el libre convencimiento del juez, quien debe realizar un análisis lógico y motivar su sentencia. Es de evocar aquí el trabajo del juez y para ello quiero epitomar a Umberto Vincenti quien dice: «el Juez es una persona naturalmente justa: recurrir al juez, decía Aristóteles en la Ética Nicomachea, es como andar a la justicia: "el Juez es como la Justicia encarnada” (2013, pág. 36).

En conclusión, retornando a nuestro discurso central sobre el derecho al silencio del imputado, podemos decir que este es neutro, el ordenamiento le reconoce un derecho de rango constitucional, el derecho del imputado de abstenerse de declarar, no puede incidir o producir consecuencias negativas al imputado, sea esta de carácter probatorio, en función de la determina- 
ción de la pena o a fin de evaluar la subsistencia de elementos a integrar los presupuesto de una medida cautelar (Stanzione, 2017, pág. 111).

El ejercicio del derecho al silencio por parte del imputado no puede constituir prueba libremente valorizada por el juez, no puede ser interpretado desfavorablemente hacia él.

Al centro de cada proceso penal hay una necesidad de saber si el acusado es culpable o inocente. En términos más técnicos, se puede decir que el objeto del proceso penal es la hipótesis avanzada por parte de la fiscalía. El proceso penal, por tanto, también constituye una especie de técnica social directa a garantizar que la reconstrucción del hecho reunido con la sentencia final puede ser considerada verdadero (Capone, 2016-2017, p. 15).

Finalmente, compartimos lo que dijo Norberto Bobbio: «los derechos pertenecen a la historia y es uno de los principales indicadores del progreso histórico, y éstas están en una continua expansión, son el resultado de una lucha por la defensa de nuevas libertades en contra de viejos poderes.» (Bobbio, 1990, pág. 23 y ss.).

\section{BIBLIOGRAFÍA}

Alvazzi del Frate, P. y Serges, G. (1992). Garantismo e inquisizione. Considerazioni sulla giustizia criminale in età moderna. La giustizia criminale nell'Italia moderna (XVI-XVIII sec.). Bolonia.

Corso, P. (2000). Diritto al silenzio: Garanzia da Difendere o Ingombro Processuale da Rimuovere? Studi en recuerdo Giandomenico Pisapia. Milán.

Beccaria, C. (2015). Tratado de los delitos y de las penas. Madrid: Universidad Carlos III de Madrid.

Bianco, A. (2016). Secondo L'art.24 della carta costituzionale la "Defesa» e' un diritto inviolabile. Diritto \& dintorni, Periodico dell'ordine Forense di Catanzaro.

Bobbio, N. (1990). L'età dei diritti. Turin.

Camaldo, L. (2001). Immagine dell'imputato in manette, presunzione di non colpevolezza e tutela della libertà morale. Cassazione penale.

Roxin, C. (2003). Derecho Procesal Penal, 25. ${ }^{a} e d$. Buenos Aires: El Puerto.

Capone, A. (2016-2017). Storia, cultura e principi del processo penale (Introduzione ad uso degli studenti). Calabria. 
Carnelutti, F. (1947). Lezioni sul processo penale, volumen II. Roma.

Catalano, E. (2011). Diritto al silenzio, right not to be questioned e tutela dalla autocriminazione. Cassazione penale. 11.

Cattaneo, M. (1995). Garantismo e Tolleranza. Fiorencia.

Cazzullo, A. (2015). La crisis della verita. Revista la sette 40. Milan.

Cavini, S. Il diritto di difesa nell'individuazione di persone e nel mandato di arresto europeo. Diritto penale e processo 2/2017.

Corso, P. (2013). Quale difesa dall'abuso nella difesa? Rivista italiana diritto e processo penale.

D’Agostino, F. (1993). Filosofia del diritto. Turin.

Dezza, E. (2013). Lezioni di storia del processo penale. Padua: Pavia University Press.

Enrico, M. (2000). Accertamenti non definitivi sulla responsabilita dell'imputato ed attenuazione della presunzione di non colpevolezza. Cassazione penale.

Fanchiotti, V. (1999). Dal casomiranda al caso dickerson lo jus tacendi continua a far discutere. Diritto penale e proceso, 4.

Ferrajoli, L. (1990). Diritto e Ragione. Teoria del Garantismo Penale. Bari.

Ferrua, P. (1988). Difesa. Digesto Penale, tomo III, Turín.

Filangieri, G. (1984). La scienza della legislazione, Benjamin Constant, commento sulla scienza della legislazione. tomo I, a Cura di Vittorio Frosini. Roma: Istituto poligrafico e zecca dello Stato.

Galati, S. y Zappala, T. (2001). Diritto Processuale Penale. Milán.

G. Capone Braga-G. (2006). Piaia. Illuminismo. Enciclopedia Filosofica. Bompiani, vol. VI.

Gardino, A. il diritto di difesa nell'istruttoria Penale. Milán; 1983.

Gopnik, A. (30 de junio del 2017). La verita, vi prego sulle bugie in letteratura. Diario la Repubblica.

Grevi, V. (1972). Nemo tenetur se detegere: interrogatorio dell'imputato e diritto al silenzio nel processo penale Italiano. Milano: Giuffrè.

Guarneri, G. (1954). Personalita e Processo Penale. Scritti Giuridici en Honor a Vincenzo Manzini, Padua.

Hobbes, T. (2006). Leviatano (o la Materia, La forma e il potere di un Stato ecclesiastico e civile) curado por Arrigo Pacchi. Laterza. 
Illuminati, G. (1988) Accusatorio ed Inquisitorio. Enciclopedia Giuridica. Treccani.

Kant, I. (2007). Fundamentación de la Metafísica de las Costumbre. Edición de Pedro M. Puerto Rico: Rosario Barbosa.

Kant, I. \& Constant, B. (2012) ¿Hay derecho a mentir? Madrid.

Marcoaldi, F. (1996). Kant e Constant: un 'duello' per la verita. Diario repubblica.it. Recuperado de https://ricerca.repubblica.it/repubblica/archivio/repubblica/1996/04/09/kant-constant-un-duello-per-la.html?refresh_ce

Musso, R. (1999). Diritto di Difensa e Difensore Negli U.S.A. Turin.

Nappi, D. (2005). Difesa Penale. Digesto Penale, tomo III. Turin.

Luparia, L. (2006). La confessione dell'imputato nel sistema processuale Penale. Milán.

Vincenti, U. (2013) Diritto e Menzogna (la questione della Giustizia in Italia). Roma.

Ramírez, E. (2004). Kant frente a Kant. Rev. Filosofía Univ. Costa Rica, XLH (106-107).

Scaccianoce, C. (2015). Il diritto di difesa tra effettività e necessità: le garanzie prevalgono nella lettura delle Sezioni Unite. Processo penale e giustizia, 6.

Stanzione, G. Autoincriminazione e Diritto al Silenzio, Probemi Attuali della Giustizia Penale. Spangher (director). Padua: Tonini; 2017.

Vassalli, G. (1960) Il diritto alla liberta Morale. Studi in Memoria di F. Vasalli, volumen II; 1960.

(1972). I metodi di ricerca della verità e la loro incidenza sulla integrità della persona umana. Rivista Penale.

Vernet, J. (2011). La dignidad en la Jurisprudencia Europea. Diritto Pubblico Comparato ed Europeo.

Vincenti, U. (2009). Diritti e dignità umana. Roma-Bari. Roma.

(2013). Diritto e Menzogna (la questione della Giustizia in Italia).

Vinciguerra, S. (1993). Diritto del ottocento, i codici preunitari e il codice di Zanardelli. Padua: Cedam.

Viola, F. (2006). Dignità umana. Enciclopedia filosófica, volumen 3. Milán; 2006.

(2008). Colloqui sulla dignità umana. Atti del Convegno internazionale (Palermo, octubre del 2007). Roma. 